\title{
Use of Coconut Charcoal and Menthone-Thiosemicarbazone Polymer as Solid Phase Materials for the Determination of $N, N$-Dimethyltryptamine, Harmine, Harmaline, Harmalol, and Tetrahydroharmine in Ayahuasca Beverage by Liquid Chromatography-Tandem Mass Spectrometry
}

\author{
Sandro Navickiene, ${ }^{(} *, a$ Luis F. S. Santos, ${ }^{a}$ Mônica C. Santos ${ }^{a}$ and Alain Gaujac $^{b}$ \\ ${ }^{a}$ Departamento de Química, Universidade Federal de Sergipe, 49100-000 São Cristóvão-SE, Brazil \\ ${ }^{b}$ Instituto Federal de Educação, Ciência e Tecnologia de Sergipe, \\ BR 101, km 9, 49100-000 São Cristóvão-SE, Brazil
}

\begin{abstract}
An extraction method based on solid-phase extraction was developed to determine the major alkaloid components, $N, N$-dimethyltryptamine, harmine, harmaline, harmalol, and tetrahydroharmine, in ayahuasca using ultra-performance liquid chromatography-tandem mass spectrometry. Coconut charcoal and menthone-thiosemicarbazone polymer were tested as new adsorbent materials. Experiments carried out at levels of 1,5, 10,50, 100, and $250 \mu \mathrm{g} \mathrm{mL}^{-1}$ resulted in recoveries in the ranges $45.3-115.7 \%$ for menthone-thiosemicarbazone and $40.6-116.2 \%$ for coconut charcoal. The detection and quantification limits ranged from 0.003 to $0.016 \mu \mathrm{gL}^{-1}$ and from 0.009 to $0.043 \mu \mathrm{g} \mathrm{mL}^{-1}$, respectively. The method developed was linear over the tested range (0.05-1.0 $\left.\mathrm{g} \mathrm{mL}^{-1}\right)$, with correlation coefficients ranging from 0.9969 to 0.9998 . The technique was applied for analysis of the compounds in an ayahuasca sample collected from a religious group located in the city of Fortaleza, obtaining concentrations in the range from 0.3 to $19.3 \mathrm{mg} \mathrm{mL}^{-1}$.
\end{abstract}

Keywords: alkaloid, ayahuasca beverage, coconut charcoal, menthone-thiosemicarbazone, solid phase extraction

\section{Introduction}

Ayahuasca is a psychoactive beverage that is usually prepared using a decoction of two plants: the leaves of the $N, N$-dimethyltryptamine (DMT)-containing chacrona (Psychotria viridis) and sections of the stem of the jagube vine (Banisteriopsis caapi). Both plant products contain $\mathrm{N}, \mathrm{N}$-dimethyltryptamine, requiring co-administration of naturally occurring monoamine oxidase inhibitors, for example $\beta$-carboline derivatives, in order to induce its psychoactive effects in humans. The tryptamine, $N, N$-dimethyltryptamine, and $\beta$-carboline derivatives (harmine, harmaline, harmalol and tetrahydroharmine) are simple indole alkaloids that are commonly present in the biota. ${ }^{1}$ Studies involving the determination of tryptamine compounds in plant matrices, as well as in ritual beverages, are essential given the current expansion in their use for religious and recreational purposes. ${ }^{2}$ In addition, the concentration levels of ayahuasca components show

*e-mail: sandnavi@ufs.br wide variability, not only from church to church, but also between different batches used in the same church. In Brazil, ayahuasca is legal if consumed during the course of religious activities, even by children and pregnant women. ${ }^{3}$ Liquid-liquid extraction (LLE),${ }^{4}$ continuousflow Soxhlet extraction, ${ }^{5}$ matrix solid phase dispersion (MSPD), ${ }^{6}$ ultrasonic solvent extraction (USE), ${ }^{7}$ solid phase microextraction (SPME), ${ }^{8}$ and solid phase extraction (SPE) with commercial $\mathrm{C} 18$ bonded silica ${ }^{9}$ have been employed for determination of tryptamine, $N, N$-dimethyltryptamine and $\beta$-carboline derivatives in plant matrices and ayahuasca, with analysis by gas chromatography-mass spectrometry, high-performance liquid chromatography, or capillary electrophoresis. ${ }^{10,11}$ In the SPE procedure, the choice of an appropriate adsorbent is a critical factor for obtaining a satisfactory recovery. ${ }^{12}$ An additional consideration is the high cost of commercially available adsorbents, making it necessary to search for suitable inexpensive alternative sorbents for SPE of alkaloids.

The aim of this study was to exploit the adsorptive potential of coconut charcoal and menthone-thiosemicarbazone as 
solid phase extraction sorbents for the determination of $\mathrm{N}, \mathrm{N}$-dimethyltryptamine, tryptamine, harmine, harmaline, harmalol, and tetrahydroharmine in ayahuasca beverage by ultra-performance liquid chromatography-tandem mass spectrometry (LC-MS/MS). To the best of our knowledge, this is the first report of the analysis of the major alkaloid components in ayahuasca beverage using an SPE procedure with coconut charcoal or menthone-thiosemicarbazone as adsorbent material. Coconut charcoal has been selected to be tested as an adsorbent material because its use contributes to minimize problems caused by incorrect disposal generated by the proliferation of vectors, occupation of large areas in landfills, gas production and soil contamination. While the menthone-thiosemicarbazone was chosen to evaluate its performance relative to commercial silica, which was previously studied. ${ }^{13}$

\section{Experimental}

\section{Chemicals and materials}

Tryptamine, harmalol, harmine, and harmaline were purchased from Sigma-Aldrich (St. Louis, MO, USA). DMT and tetrahydroharmine were prepared according to the methods described by Gaujac et al..$^{14}$ and Callaway et al. ${ }^{15}$ respectively. The LC-MS-grade solvents acetonitrile, methanol, and formic acid were purchased from Tedia (Fairfield, OH, USA). The HPLC grade solvent dimethyl sulfoxide (DMSO) was purchased from J.T.Baker (Pennsylvania, USA). Deionized water was generated on-site using a Milli-Q gradient system (Millipore, Bedford, MA, USA).

\section{Sample preparation}

Ayahuasca samples were prepared from specimens of Banisteriopsis caapi stems and Psychotria viridis leaves by members of a religious group located in the city of Fortaleza, Ceará State, Brazil, according to the method reported by Santos et al. ${ }^{13}$ Aqueous decoctions of the plants were prepared from harvested material. At the end of the 20-h decoction, the extracts were bottled, frozen, and shipped to the Department of Chemistry at the Federal University of Sergipe.

\section{Sample extraction and clean-up procedure}

A menthone-thiosemicarbazone or coconut charcoal cartridge was preconditioned with $4 \mathrm{~mL}$ of methanol followed by $4 \mathrm{~mL}$ of $1 \mathrm{~mol} \mathrm{~L}^{-1}$ hydrochloric acid solution. The cartridge was placed on top of a vacuum block. A
$20 \mathrm{~mL}$ aliquot of ayahuasca sample (at $\mathrm{pH} 8$, adjusted using $0.01 \mathrm{~mol} \mathrm{~L}^{-1} \mathrm{NaOH}$ solution) was transferred to the cartridge at a flow-rate of $0.5 \mathrm{~mL} \mathrm{~min}^{-1}$, and the solid phase was allowed to dry for $5 \mathrm{~min}$. The alkaloids were then eluted with $3 \mathrm{~mL}$ (for coconut charcoal as adsorbent material) or $6 \mathrm{~mL}$ (for menthone-thiosemicarbazone as adsorbent material) of acidified methanol ( $\mathrm{pH} 3)$. The eluent was collected in a round-bottom flask and was concentrated to a volume of $1 \mathrm{~mL}$ using a gentle stream of nitrogen. Prior to injection into the LC-MS/MS system, the extract was filtered through a $0.20 \mu \mathrm{m}$ pore size nylon filter (Sartorius, Germany) and centrifuged for $5 \mathrm{~min}$ at $2100 \mathrm{rpm}$. A $1 \mu \mathrm{L}$ aliquot was analyzed in the LC-MS/MS system. For a final volume of $1 \mathrm{~mL}$, the concentration factor was 20 . The samples were analyzed in triplicate $(n=3)$.

\section{Synthesis and characterization of menthone- thiosemicarbazone}

Menthone-thiosemicarbazone crystals were synthesized and characterized according to the methodology reported by de Oliveira et al. ${ }^{16}$ with minor modification. In a hydrochloric acid-catalyzed reaction, a mixture of (-)-menthone $(10 \mathrm{mmol})$ and 4 -methyl-3-thiosemicarbazide $(10 \mathrm{mmol})$ in ethanol $(80 \mathrm{~mL})$ was refluxed for $5 \mathrm{~h}$. After cooling and filtering, the compound was obtained. Colorless plates were obtained by slow evaporation of a solution in DMSO. Crystal data, data collection, and structure refinement details are summarized in Table S1 (Supplementary Information).

\section{Coconut charcoal production}

The biomass was pyrolyzed at $500{ }^{\circ} \mathrm{C}$ in the laboratory at the Department of Chemistry of the Federal University of Santa Catarina, yielding the coconut charcoal. The pyrolysis unit consisted of a cylindrical furnace with a $30 \mathrm{~cm}$ high vertical stainless steel reactor with an inner diameter of $3.6 \mathrm{~cm}$. The biomass was ground to a particle size of about $10 \mathrm{~mm}$ and was then added into the reactor tube to a height of about $25 \mathrm{~cm}$, followed by flushing with $\mathrm{N}_{2}$ at a gas flow rate of $4 \mathrm{~L} \mathrm{~min}{ }^{-1}$. After a total residence time of $30 \mathrm{~min}$ at the selected temperature of $500{ }^{\circ} \mathrm{C}$, the reactor tube was cooled and the charcoal produced was collected, weighed, and stored in glass containers at room temperature.

Instrumentation

Chromatographic analyses were performed using an Acquity UPLC system (Waters, Milford, USA) equipped with a quaternary solvent delivery module, degasser, autosampler, and column heater. Chromatographic 
separations were performed using a Waters Acquity CSH Phenyl-Hexyl column $(100 \times 2.1 \mathrm{~mm}, 1.7 \mu \mathrm{m}$ particle size $)$. MS/MS detection was performed using a Xevo TQD tandem quadrupole mass spectrometer (Waters, Manchester, UK), coupled to an electrospray ionization (ESI) interface and operated in positive ion mode. The source parameters were a capillary voltage of $3.0 \mathrm{kV}$, source temperature of $150^{\circ} \mathrm{C}$, and desolvation gas temperature of $450{ }^{\circ} \mathrm{C}$. Nitrogen was used as the cone and desolvation gases, at flow rates of 900 and $50 \mathrm{~L} \mathrm{~h}^{-1}$, respectively. Analytical instrument control, data acquisition, and data treatment were performed with MassLynx v. 4.1 software (Micromass, Manchester, UK). Mobile phase eluent A was composed of ultrapure water containing $0.1 \%$ formic acid. Eluent B was composed of methanol with $0.1 \%$ formic acid. A linear gradient was employed, with $5 \%$ eluent $\mathrm{B}$ (at $0 \mathrm{~min}$ ) increasing to $100 \%$ eluent $\mathrm{B}$ (at $8 \mathrm{~min}$ ), returning to $5 \%$ at $10 \mathrm{~min}$ and maintaining at $5 \%$ up to $12 \mathrm{~min}$, when a new injection was made. The flow rate was $0.3 \mathrm{~mL} \mathrm{~min}{ }^{-1}$ and the injection volume was $1 \mu \mathrm{L}$. Multiple reaction monitoring (MRM) experiments were performed, with auto-dwell times for all the alkaloids. The highest intensity transition was used for quantification, and the second most intense was used for confirmation. Collision induced dissociation (CID) was performed using argon as the collision gas, at a pressure of $4 \times 10^{-3} \mathrm{mbar}$ and flow-rate of $0.15 \mathrm{~mL} \mathrm{~min}^{-1}$. Optimization of the collision energy for each individual alkaloid was achieved by direct infusion into the MS. The precursor and product ions were monitored according to the retention time. The retention times, cone voltages, and collision energies in positive ESI mode used for quantification and confirmation of the analytes are shown in Table 1.

\section{Results and Discussion}

\section{LC-MS/MS conditions}

The mass spectrometer was operated using ESI(+), in dynamic MRM mode, with $[\mathrm{M}+\mathrm{H}]^{+}$ions as the precursor ions. All the MRM analyses were performed at unit resolution for both quadrupoles. Optimization of the precursor and product ions was achieved by infusion of $10 \mu \mathrm{L}$ aliquots of the individual alkaloid solutions directly into the mass spectrometer. Different fragmentation voltages were applied and the optimal voltages ranged between $16 \mathrm{~V}$ (for tryptamine) and $45 \mathrm{~V}$ (for harmine, harmaline and harmalol). The collision energies were investigated and ranged from 5 to $50 \mathrm{~V}$. The most intense transition was used for quantification, while the second most intense transition was used for confirmation. These parameters are presented in Table 1. For optimization of the chromatographic conditions, two different mobile phases (acetonitrile and methanol) were tested, and the best sensitivity and chromatographic peaks were obtained using methanol. The flow rate, injection volume, and column temperature were also optimized in order to achieve a fast and reliable separation, with selection of values of $0.3 \mathrm{~mL} \mathrm{~min}{ }^{-1}, 1 \mu \mathrm{L}$, and $40{ }^{\circ} \mathrm{C}$, respectively. All the compounds were eluted with high sensitivity and selectivity in less than 15 min, including the cleaning and re-equilibration step (Figure 1).

\section{Optimization of the extraction procedure}

In an earlier work,,$^{13}$ our group studied the use of commercial silica as the sorbent material and acidified methanol as the eluting solvent, using an SPE procedure for the recovery of different alkaloids from ayahuasca beverages. Analogously, in the present study, evaluation was made through the use of coconut charcoal and menthonethiosemicarbazone polymer as alternative sorbents for the determination of harmine, harmaline, tetrahydroharmine, harmalol, tryptamine, and DMT in ayahuasca beverage. The effect of the amount of adsorbents in the solution on the recoveries of the alkaloids was investigated using values of 125 and $250 \mathrm{mg}$. The optimum amounts selected were $125 \mathrm{mg}$ (coconut charcoal) and $250 \mathrm{mg}$ (menthonethiosemicarbazone polymer). Indole alkaloids are basic

Table 1. Retention times and mass spectrometric parameters for the multiple reaction monitoring (MRM) mode for the analysis of alkaloids by LC-ESI-MS/MS

\begin{tabular}{|c|c|c|c|c|c|c|c|c|}
\hline \multirow{3}{*}{ Alkaloid } & \multirow{3}{*}{$\begin{array}{l}\text { Retention } \\
\text { time / min }\end{array}$} & \multirow{3}{*}{$\begin{array}{l}\text { Precursor } \\
\text { ion }(m / z)\end{array}$} & \multirow{3}{*}{$\begin{array}{c}\text { Cone } \\
\text { voltage / V }\end{array}$} & \multirow{3}{*}{$\begin{array}{c}\text { Dwell } \\
\text { time / s }\end{array}$} & \multicolumn{4}{|c|}{ MRM transition } \\
\hline & & & & & \multicolumn{2}{|c|}{ Quantification } & \multicolumn{2}{|c|}{ Confirmation } \\
\hline & & & & & $\begin{array}{c}\text { Production } \\
\text { ion }(m / z)\end{array}$ & $\begin{array}{c}\text { Collision } \\
\text { energy / eV }\end{array}$ & $\begin{array}{c}\text { Production } \\
\text { ion }(m / z)\end{array}$ & $\begin{array}{c}\text { Collision } \\
\text { energy / eV }\end{array}$ \\
\hline Tryptamine & 0.74 & 161.0 & 16 & 0.080 & 144.0 & 10 & 117.3 & 23 \\
\hline$N, N$-Dimethyltryptamine & 1.08 & 189.1 & 23 & 0.080 & 57.9 & 12 & 144.1 & 17 \\
\hline Harmalol & 1.90 & 200.9 & 45 & 0.052 & 160.0 & 23 & 67.9 & 26 \\
\hline Tetrahydroharmine & 2.62 & 217.0 & 20 & 0.052 & 188.0 & 14 & 200.1 & 12 \\
\hline Harmaline & 4.46 & 215.0 & 45 & 0.080 & 200.0 & 22 & 173.9 & 23 \\
\hline Harmine & 4.83 & 212.9 & 45 & 0.080 & 170.1 & 30 & 198.0 & 23 \\
\hline
\end{tabular}




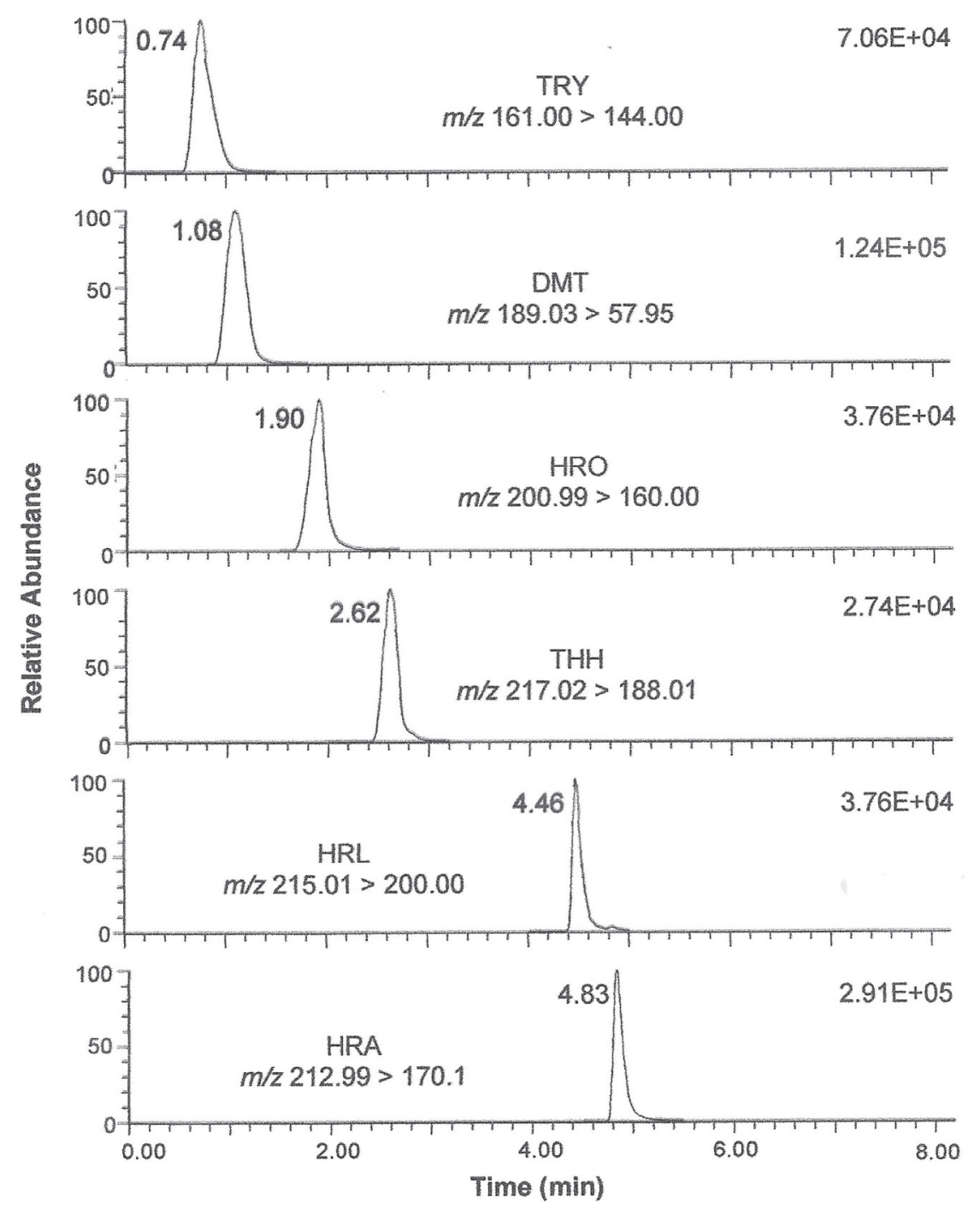

Figure 1. Selected ion transitions, and representative multiple reaction monitoring (MRM) chromatograms for the alkaloids at concentrations of $500 \mathrm{ng} \mathrm{mL}$, obtained by LC-MS/MS (ESI positive ion mode). Peak identification: TRY: tryptamine; DMT: $N, N$-dimethyltryptamine; HRO: harmalol; THH: tetrahydroharmine; HRL: harmaline; HRA: harmine.

compounds, and $\mathrm{pH}$ of the solution was expected to have effect on their recovery. Two volumes $(3$ and $6 \mathrm{~mL}$ ) of the elution solvent (acidified methanol, $\mathrm{pH} 3$ ) were tested. When the coconut charcoal was used as the adsorbent in the SPE procedure, increasing the solvent volume from 3 to $6 \mathrm{~mL}$ resulted in improved alkaloid recoveries, with values in the range from $51.2 \pm 0.8 \%$ to $63.7 \pm 2.7 \%(3 \mathrm{~mL})$ and from $70.1 \pm 2.7 \%$ to $91.9 \pm 1.2 \%$ ( $6 \mathrm{~mL}$ ). A volume of $6 \mathrm{~mL}$ was therefore selected for use with the coconut charcoal. However, when the menthone-thiosemicarbazone polymer was used as the adsorbent material, $3 \mathrm{~mL}$ was selected as the optimum elution volume, since the alkaloid recovery decreased when the volume was increased to $6 \mathrm{~mL}$, with values in the ranges from $69.7 \pm 3.2 \%$ to $97.5 \pm 1.9 \%$ and from $54.1 \pm 1.5 \%$ to $93.3 \pm 1.3 \%$, respectively. The results are shown in Table 2.

\section{Method validation}

For calibration purposes, ten solutions containing increasing concentrations of alkaloids in the range from 5 to $1000 \mathrm{ng} \mathrm{mL}^{-1}$ were analyzed in triplicate. The slope and intercept values, together with their standard deviations, were determined using regression analyses. Excellent linear regression coefficients were obtained for the different alkaloids, ranging from 0.9969 to 0.9998 (Table 3).

Recovery experiments were carried out at six fortification levels $\left(1,5,10,50,100\right.$, and $\left.250 \mu \mathrm{gL}^{-1}, \mathrm{n}=3\right)$. Analyses were performed by LC-MS/MS, with external calibration. For charcoal coconut, the average recoveries ranged from 70.2 to $112.6 \%$, with relative standard deviations (RSD) of 0.7 to $10.7 \%$, while for the menthone-thiosemicarbazone polymer, the average recoveries were from 72.4 to 
Table 2. Influence of different solid-phase adsorbents and adsorbent amount on recovery of the alkaloids at concentrations of $100 \mu \mathrm{g} \mathrm{mL}^{-1}$

\begin{tabular}{lcccccccc}
\hline & \multicolumn{8}{c}{ Mean recovery \pm RSD $(\mathrm{n}=3) / \%$} \\
\cline { 2 - 8 } & \multicolumn{9}{c}{ Coconut charcoal } & \multicolumn{4}{c}{ SiMen(M)TSC } \\
\hline Amount / mg & 250 & 250 & 125 & 125 & 250 & 250 & 125 & 125 \\
Elution volume / $\mathrm{mL}$ & 3 & 6 & 3 & 6 & 3 & 6 & 3 & 6 \\
Tryptamine & $56.7 \pm 1.6$ & $40.1 \pm 2.5$ & $56.9 \pm 1.2$ & $73.7 \pm 2.6$ & $79.9 \pm 2.4$ & $62.3 \pm 0.7$ & $50.7 \pm 0.9$ & $52.3 \pm 2.2$ \\
$N, N$-Dimethyltryptamine & $62.2 \pm 0.8$ & $55.6 \pm 1.4$ & $62.1 \pm 2.4$ & $74.4 \pm 1.3$ & $93.3 \pm 2.3$ & $88.4 \pm 3.6$ & $71.4 \pm 4.2$ & $72.2 \pm 1.5$ \\
Harmalol & $48.2 \pm 2.9$ & $20.9 \pm 3.3$ & $56.2 \pm 1.8$ & $70.1 \pm 2.7$ & $69.7 \pm 3.2$ & $54.1 \pm 1.5$ & $33.3 \pm 2.5$ & $40.7 \pm 1.1$ \\
Harmine & $54.3 \pm 2.2$ & $43.5 \pm 1.7$ & $63.7 \pm 2.7$ & $91.9 \pm 1.2$ & $78.9 \pm 4.4$ & $75.8 \pm 2.9$ & $46.3 \pm 1.8$ & $53.9 \pm 2.6$ \\
Harmaline & $51.6 \pm 3.5$ & $50.9 \pm 2.9$ & $60.5 \pm 3.5$ & $78.9 \pm 2.9$ & $83.6 \pm 3.7$ & $79.4 \pm 2.4$ & $56.2 \pm 2.6$ & $60.8 \pm 2.4$ \\
Tetrahydroharmine & $59.5 \pm 1.2$ & $62.2 \pm 2.6$ & $51.2 \pm 0.8$ & $76.6 \pm 1.4$ & $97.5 \pm 1.9$ & $93.3 \pm 1.3$ & $60.8 \pm 1.1$ & $63.1 \pm 0.9$ \\
\hline
\end{tabular}

RSD: relative standard deviation; SiMen(M)TSC: 2-[(E)-(2S,5R)-2-isopropyl-5-methylcyclohexyl-idene]- $N$-methylhydrazine-1-carbothioamide.

Table 3. Linear regression parameters obtained for different adsorbent materials using the alkaloids concentrations in the range from 0.05 to $1.0 \mu \mathrm{g} \mathrm{mL}^{-1}$

\begin{tabular}{|c|c|c|c|c|c|c|c|c|}
\hline \multirow{3}{*}{ Alkaloid } & \multicolumn{4}{|c|}{ Coconut charcoal } & \multicolumn{4}{|c|}{ SiMen(M)TSC } \\
\hline & \multirow{2}{*}{ Regression curve } & \multirow{2}{*}{$\mathrm{R}^{2}$} & \multicolumn{2}{|c|}{ SD } & \multirow{2}{*}{ Regression curve } & \multirow{2}{*}{$\mathrm{R}^{2}$} & \multicolumn{2}{|c|}{ SD } \\
\hline & & & Slope & Intercept & & & Slope & Intercept \\
\hline Tryptamine & $y=18116 x-13119$ & 0.9996 & 72.3 & 262.2 & $y=19024 x-44022$ & 0.9995 & 0.3 & 58.5 \\
\hline$N, N$-Dimethyltryptamine & $y=17943 x-26973$ & 0.9987 & 83.9 & 183.2 & $y=19226 x-30233$ & 0.9996 & 58.3 & 270.0 \\
\hline Harmalol & $y=39634 x-262712$ & 0.9985 & 9.1 & 688.9 & $y=39480 x-195100$ & 0.9969 & 55.5 & 847.2 \\
\hline Harmine & $y=10583 x+32650$ & 0.9993 & 141.8 & 333.5 & $y=95426 x-18206$ & 0.9992 & 87.9 & 631.8 \\
\hline Harmaline & $y=65436 x-147207$ & 0.9998 & 34.8 & 417.8 & $y=65419 x+213058$ & 0.9979 & 27.6 & 411.4 \\
\hline Tetrahydroharmine & $y=63204 x-187277$ & 0.9995 & 12.5 & 270.8 & $y=66258 x+128083$ & 0.9988 & 50.3 & 211.1 \\
\hline
\end{tabular}

$\mathrm{R}^{2}$ : determination coefficient; SD: standard deviation.

$115.7 \%$, with RSD of 0.4 to $9.6 \%$. The values obtained were generally satisfactory, considering the recovery range normally considered acceptable (70-120\%). ${ }^{17}$ The recoveries of the alkaloids from ayahuasca samples indicated that the use of charcoal coconut or menthonethiosemicarbazone as adsorbent material in solid phase extraction enabled accurate and precise quantification of the alkaloids in the beverage. Direct comparison of the alternative adsorbents with commercial silica showed similar extractions for the alkaloids investigated (Table 4).

The limits of detection (LOD) were calculated considering the standard deviation of the analytical noise (a value of three times the standard deviation of the blank) and the slope of the regression line. The limits of quantification (LOQ) were determined as the lowest concentration giving a response of ten times the average of the baseline noise, calculated using unfortified samples. ${ }^{16}$ For coconut charcoal, the LOD values for the compounds ranged from 0.003 to $0.009 \mu \mathrm{g} \mathrm{mL}^{-1}$, while the LOQ values were from 0.011 to $0.03 \mu \mathrm{g} \mathrm{mL}^{-1}$. For the menthone-thiosemicarbazone polymer, the LOD values ranged from 0.005 to $0.014 \mu \mathrm{gLL}^{-1}$, while the LOQ values were from 0.016 to $0.043 \mu \mathrm{g} \mathrm{mL} \mathrm{m}^{-1}$ (Table 5).
Matrix effects were investigated by comparing the slopes of the analytical curves generated from alkaloid standards in methanol with those for the standards in a blank matrix. The matrix effect was negligible for tetrahydroharmine $(<5 \%)$, while the values obtained for the other compounds were $17 \%$ ( $N, N$-dimethyltryptamine), $16 \%$ (tryptamine), $16 \%$ (harmalol), $20 \%$ (harmine), and $12 \%$ (harmaline). Matrix effects were minimized by using the matrix itself to generate the analytical curves. The repeatability (intra-assay precision) of the method was assessed using five successive analyses of $1 \mu \mathrm{g} \mathrm{mL}^{-1}$ alkaloid standard solutions, resulting in relative standard deviations in the range $0.1-1.9 \%$. The intermediate precision (as between-day precision) was determined by analyzing the same standard solution on three alternate days, and the RSD values obtained were lower than $1.8 \%$.

\section{Method application}

Four samples of ayahuasca were collected from a religious group in the city of Fortaleza, Brazil. The samples were analyzed by the SPE method, with extraction 
Table 4. Recoveries of alkaloids at six concentration levels obtained using the proposed method with commercial and alternative adsorbent materials

\begin{tabular}{|c|c|c|c|c|}
\hline \multirow{2}{*}{ Alkaloid } & \multirow{2}{*}{$\begin{array}{l}\text { Fortification level / } \\
\qquad\left(\mu \mathrm{g} \mathrm{mL}^{-1}\right)\end{array}$} & \multicolumn{3}{|c|}{ Average recovery $\pm \mathrm{RSD} / \%$} \\
\hline & & Commercial silica $^{\mathrm{a}}$ & Coconut charcoal & SiMen(M)TSC \\
\hline \multirow{6}{*}{ Tryptamine } & 1 & $76.6 \pm 9.6$ & $86.1 \pm 3.6$ & $74.7 \pm 2.3$ \\
\hline & 5 & $92.7 \pm 6.1$ & $79.7 \pm 2.8$ & $76.1 \pm 2.6$ \\
\hline & 10 & $106.9 \pm 6.1$ & $70.2 \pm 1.5$ & $78.3 \pm 1.5$ \\
\hline & 50 & $86.9 \pm 5.8$ & $90.5 \pm 3.5$ & $72.4 \pm 3.5$ \\
\hline & 100 & $82.7 \pm 7.9$ & $71.4 \pm 4.9$ & $76.7 \pm 5.1$ \\
\hline & 250 & $94.3 \pm 6.4$ & $89.2 \pm 1.5$ & $76.2 \pm 3.6$ \\
\hline \multirow{6}{*}{$\mathrm{N}, \mathrm{N}$-Dimethyltryptamine } & 1 & $69.5 \pm 6.1$ & $97.5 \pm 5.3$ & $63.9 \pm 9.6$ \\
\hline & 5 & $82.9 \pm 7.2$ & $79.5 \pm 4.7$ & $78.6 \pm 3.9$ \\
\hline & 10 & $103.6 \pm 6.2$ & $79.9 \pm 2.4$ & $80.8 \pm 0.5$ \\
\hline & 50 & $84.1 \pm 6.9$ & $92.7 \pm 4.3$ & $82.4 \pm 4.8$ \\
\hline & 100 & $93.3 \pm 2.5$ & $71.7 \pm 1.1$ & $84.9 \pm 0.8$ \\
\hline & 250 & $112.6 \pm 1.8$ & $112.6 \pm 1.8$ & $82.9 \pm 2.4$ \\
\hline \multirow{6}{*}{ Harmalol } & 1 & $45.0 \pm 5.5$ & $40.6 \pm 3.4$ & $45.3 \pm 8.8$ \\
\hline & 5 & $59.4 \pm 2.3$ & $43.4 \pm 1.1$ & $58.2 \pm 1.9$ \\
\hline & 10 & $71.7 \pm 2.1$ & $69.3 \pm 1.0$ & $72.5 \pm 2.8$ \\
\hline & 50 & $79.9 \pm 1.9$ & $74.8 \pm 10.7$ & $86.5 \pm 0.4$ \\
\hline & 100 & $81.0 \pm 3.1$ & $94.9 \pm 3.9$ & $79.9 \pm 8.7$ \\
\hline & 250 & $95.7 \pm 9.8$ & $116.2 \pm 4.3$ & $88.2 \pm 1.3$ \\
\hline \multirow{6}{*}{ Harmine } & 1 & $84.5 \pm 9.5$ & $108.9 \pm 1.5$ & $77.1 \pm 3.4$ \\
\hline & 5 & $86.0 \pm 2.8$ & $85.4 \pm 6.3$ & $79.3 \pm 2.5$ \\
\hline & 10 & $101.3 \pm 2.4$ & $89.2 \pm 9.5$ & $77.0 \pm 0.8$ \\
\hline & 50 & $88.2 \pm 3.0$ & $105.4 \pm 3.6$ & $78.9 \pm 1.1$ \\
\hline & 100 & $91.6 \pm 4.2$ & $85.1 \pm 1.7$ & $80.9 \pm 0.9$ \\
\hline & 250 & $103.7 \pm 3.2$ & $101.4 \pm 0.9$ & $77.9 \pm 2.1$ \\
\hline \multirow{6}{*}{ Harmaline } & 1 & $77.9 \pm 7.7$ & $76,5 \pm 1.6$ & $115.7 \pm 2.1$ \\
\hline & 5 & $82.5 \pm 6.8$ & $74.5 \pm 1.3$ & $88.2 \pm 2.4$ \\
\hline & 10 & $95.0 \pm 5.5$ & $72.2 \pm 3.3$ & $78.9 \pm 1.2$ \\
\hline & 50 & $83.0 \pm 5.1$ & $88.1 \pm 2.0$ & $90.6 \pm 0.5$ \\
\hline & 100 & $89.7 \pm 6.1$ & $75.1 \pm 2.1$ & $80.5 \pm 2.2$ \\
\hline & 250 & $98.7 \pm 2.6$ & $94.8 \pm 0.8$ & $85.2 \pm 3.3$ \\
\hline \multirow{6}{*}{ Tetrahydroharmine } & 1 & $73.5 \pm 3.1$ & $76.1 \pm 1.4$ & $103.6 \pm 6.0$ \\
\hline & 5 & $79.9 \pm 5.8$ & $74.1 \pm 0.7$ & $79.6 \pm 3.3$ \\
\hline & 10 & $96.8 \pm 1.1$ & $84.8 \pm 2.4$ & $79.6 \pm 3.1$ \\
\hline & 50 & $87.7 \pm 2.9$ & $85.8 \pm 3.7$ & $77.2 \pm 7.1$ \\
\hline & 100 & $94.6 \pm 1.8$ & $75.5 \pm 0.4$ & $86.3 \pm 1.5$ \\
\hline & 250 & $107.4 \pm 2.9$ & $92.7 \pm 1.4$ & $83.2 \pm 1.2$ \\
\hline
\end{tabular}

${ }^{a}$ Description of the solid phase extraction (SPE) procedure using commercial silica as adsorbent material. ${ }^{14}$ RSD: relative standard deviation; SiMen(M) TSC: 2-[(E)-(2S,5R)-2-isopropyl-5-methylcyclohexyl-idene]- $N$-methylhydrazine-1-carbothioamide.

using the alternative adsorbent materials followed by LC-MS/MS analysis. When the coconut charcoal was used as the adsorbent, the harmine, harmaline, tetrahydroharmine, harmalol, and DMT concentrations in the samples ranged from 0.5 to $19.2 \mathrm{mg} \mathrm{mL}^{-1}$, while for menthone-thiosemicarbazone as adsorbent, the values ranged from 0.3 to $19.3 \mathrm{mg} \mathrm{mL}^{-1}$. The coconut charcoal provided more effective adsorption of harmalol (Table 6). 
Table 5. Limits of detection and quantification for the alkaloids in ayahuasca using the proposed SPE method with different adsorbent materials

\begin{tabular}{lcccc}
\hline \multirow{2}{*}{ Alkaloid } & \multicolumn{2}{c}{ Coconut charcoal } & \multicolumn{2}{c}{ SiMen $(\mathrm{M}) \mathrm{TSC}$} \\
\cline { 2 - 5 } Tryptamine & $\mathrm{LOD} /\left(\mu \mathrm{g} \mathrm{mL} \mathrm{mL}^{-1}\right)$ & $\mathrm{LOQ} /(\mu \mathrm{g} \mathrm{mL}-1)$ & $\left.\mathrm{LOD} /(\mu \mathrm{g} \mathrm{mL})^{-1}\right)$ & $\left.\mathrm{LOQ} /(\mu \mathrm{g} \mathrm{mL})^{-1}\right)$ \\
$N, N$-Dimethyltryptamine & 0.004 & 0.014 & 0.006 & 0.017 \\
Harmalol & 0.009 & 0.028 & 0.005 & 0.016 \\
Harmine & 0.009 & 0.030 & 0.014 & 0.043 \\
Harmaline & 0.006 & 0.020 & 0.007 & 0.021 \\
Tetrahydroharmine & 0.003 & 0.011 & 0.011 & 0.035 \\
\hline
\end{tabular}

SiMen(M)TSC: 2-[(E)-(2S,5R)-2-isopropyl-5-methylcyclohexyl-idene]- $N$-methylhydrazine-1-carbothioamide; LOD: limit of detection; LOQ: limit of quantification.

Table 6. Concentration of alkaloids found in ayahuasca samples using coconut charcoal, menthone-thiosemicarbazone, and commercial silica as solid phase extraction adsorbent

\begin{tabular}{lccc}
\hline & & Concentration / $\left(\mathrm{mg} \mathrm{mL}^{-1}\right)$ \\
\cline { 2 - 4 } Alkaloid & $\begin{array}{c}\text { Coconut charcoal } \\
(125 \mathrm{mg})\end{array}$ & $\begin{array}{c}\text { SiMen(M)TSC } \\
(250 \mathrm{mg})\end{array}$ & $\begin{array}{c}\text { Commercial silica } \\
(500 \mathrm{mg})\end{array}$ \\
\hline$N, N$-Dimethyltryptamine & 1.4 & 2.6 & 5.2 \\
Harmalol & 0.5 & 0.3 & 0.3 \\
Harmine & 4.4 & 6.1 & 9.2 \\
Harmaline & 10.7 & 11.3 & 17.7 \\
Tetrahydroharmine & 19.2 & 19.3 & 36.7 \\
\hline
\end{tabular}

SiMen(M)TSC: 2-[(E)-(2S,5R)-2-isopropyl-5-methylcyclohexyl-idene]- $N$-methylhydrazine-1-carbothioamide.

The absence of the alkaloid tryptamine could be explained by its bioconversion to DMT in the plants. ${ }^{18}$ The results demonstrated that menthone-thiosemicarbazone or coconut charcoal could be used as the extractant phase for determination of these alkaloids in ayahuasca beverages, since the concentrations were in agreement with those obtained using commercial silica as the adsorbent material ( 0.3 to $\left.36.7 \mathrm{mg} \mathrm{mL}^{-1}\right) .{ }^{13}$ For these selected alkaloids, some studies have shown concentration range from 0.01 to $46.7 \mathrm{mg} \mathrm{mL}^{-1}$. $^{6,9,19}$ The discrepancy in alkaloid concentration can be explained by the different methods of preparation as well as the amounts and proportions of the source plants. ${ }^{8,20}$

\section{Conclusions}

The main goal of the present work was successfully achieved. This is the first report of menthonethiosemicarbazone or coconut charcoal being used for determination of alkaloids of ayahuasca beverage. For such purpose, SPE method with menthone-thiosemicarbazone or coconut charcoal as the adsorbent material allows to obtain satisfactory results in terms of analyte recovery and repeatability (RSD, in percentage). The proposed methodology was optimized and validated and showed successful analytical performance for the analysis of $\mathrm{N}, \mathrm{N}$-dimethyltryptamine, harmine, harmaline, harmalol, and tetrahydroharmine in ayahuasca beverage samples using small amounts of coconut charcoal (125 mg) or menthone-thiosemicarbazone $(250 \mathrm{mg}$ ) for SPE. The findings indicated that the SPE method with these adsorbents proved that coconut charcoal or menthonethiosemicarbazone could be an alternative material to replace commercial silica sorbent phase, that required an amount of $500 \mathrm{mg}$ to obtain comparable results.

\section{Supplementary Information}

Supplementary information is available free of charge at http://jbcs.org.br as PDF file.

\section{Acknowledgments}

The authors wish to thank Dr Adriano Bof de Oliveira and MSc Renan Lira de Farias for providing the menthone-thiosemicarbazone material, and Dr Antonio Salvio Mangrich and MSc Tassya Thaísa da Silva Matos for providing the coconut charcoal material. We are also 
grateful to Dr Mark Ian Collins for providing the ayahuasca samples.

\section{References}

1. Yritia, M.; Ortuño, J.; Ramirez, A.; Castillo, A.; Alfaro, Y.; de la Torre, R.; Barbanoj, M. J.; J. Chromatogr. B 2002, 709, 271.

2. Sklerov, J.; Levine, B.; Moore, K. A.; King, T.; Fowler, D.; J. Anal. Toxicol. 2005, 29, 838.

3. Conselho Nacional de Políticas sobre Drogas (CONAD); Resolução No. 1 de 25 de janeiro de 2010, Dispõe sobre a Observância, pelos Órgãos da Administração Pública, das Decisões do Conselho Nacional de Políticas sobre Drogas CONAD sobre Normas e Procedimentos Compatíveis com o Uso Religioso da Ayahuasca e dos Princípios Deontológicos que o Informam; Diário Oficial da União (DOU): Brasília, 2010. Available at https://pt.scribd.com/document/313586436/ Ayahuasca-Lei, accessed in September 2017.

4. Pichini, S.; Marchei, E.; Garcia-Algar, O.; Gomez, A.; Di Giovannandrea, R.; Pacifici, R.; J. Pharm. Biomed. Anal. 2014, 100, 284

5. Nicasio, M. P.; Villarreal, M. L.; Gillet, F.; Bensaddek, L.; Fliniaux, M. A.; Nat. Prod. Res. 2005, 19, 61.

6. Pires, A. P. S.; Oliveira, C. D. R.; Moura, S.; Dörr, F. A.; Silva, W. A. E.; Yonamine, M.; Phytochem. Anal. 2009, 20, 149.

7. Callaway, J. C.; Brito, G. S.; Neves, E. S.; J. Psychoact. Drugs 2005, 37, 151.

8. Gaujac, A.; Dempster, N.; Navickiene, S.; Brandt, S. D.; Andrade, J. B.; Talanta 2013, 106, 394.
9. McIlhenny, E. H.; Pipkin, K. E.; Standish, L. J.; Wechkin, H. A.; Strassman, R.; Barker, S. A.; J. Chromatogr. A 2009, 1216, 8960.

10. Tascón, M.; Benavente, F.; Vizioli, N. M.; Gagliardi, L. G.; Anal. Chim. Acta 2017, 954, 60.

11. Simpson, N. J. K.; Solid-Phase Extraction: Principles, Techniques and Applications, $1^{\text {st }}$ ed.; CRC Press: New York, USA, 2000.

12. Martins, C. P. B.; Freeman, S.; Alder, J. F.; Passie, T.; Brandt, S. D.; TrAC, Trends Anal. Chem. 2010, 29, 285.

13. Santos, M. C.; Gaujac, A.; Navickiene, S.; J. AOAC Int. 2017, 100,820 .

14. Gaujac, A.; Martinez, S. T.; Gomes, A. A.; Andrade, S. J.; Pinto, A. C.; David, J. M.; Navickiene, S.; Andrade, J. B.; Microchem. J. 2013, 109, 78 .

15. Callaway, J. C.; Raymon, L. P.; Hearn, W. L.; McKenna, D. J.; Grob, C. S.; Brito, G. S.; J. Anal. Toxicol. 1996, 20, 492.

16. de Oliveira, A. B.; Beck, J.; Daniels, J.; de Farias, R. L.; IUCrData 2016, 1, x160459.

17. Bliesner, D. M.; Validating Chromatographic Methods - A Practical Guide, $1^{\text {st }}$ ed.; Wiley-Interscience: New Jersey, USA, 2006.

18. Dewick, P. M.; Medicinal Natural Products: A Biosynthetic Approach, $1^{\text {st }}$ ed.; John Wiley \& Sons: New York, USA, 2001.

19. McKenna, D. J.; J. Ethnopharmacol. 1984, 10, 195.

20. McKenna, D. J.; Pharmacol. Ther. 2004, 102, 111.

Submitted: June 15, 2018

Published online: August 30, 2018 